\title{
18. New Ways of Engaging Citizens in Service Delivery
}

\author{
Nicole Pietrucha and Jo Sammut
}

Nicole Pietrucha: Much of this volume concerns engaging citizens through notions such as co-design and co-design practice. But, how do we actually build those frameworks and how do we think about this on the ground as a real practice? In my contribution I will attempt to answer some of these questions in relation to the work we are doing in the Commonwealth Department of Human Services (DHS) about building co-design capability.

First though, I need to stress the fact that this work is in its infant stages. We started our project around June 2010, so, in fact, many of the questions readers may have concerning co-design I cannot yet answer in relation to our own project, because we are yet to fully test and implement it. Indeed, as with many in this field, we are still grappling with questions concerning whether co-design works, and how to approach issues associated in the future.

Before such issues can be explored, some context is required. The co-design project is part of a broader initiative that is happening in the portfolio on service delivery reform, and there are close to 20 large associated projects, one of which concerns co-design.

This project draws upon an already strong tradition of engagement that exists in the department; of working with stakeholders and of having relationships at a local level. But, the challenge for me and the people that work with me in DHS, has been how to rectify existing engagement processes that had developed badly: how would we incorporate more community input into policy processes to create effective co-design; what are the tools and techniques we need to introduce into the portfolio to support that work?

In the initial stages of this project we have been focusing on identifying the core framework that the portfolio needs to improve engagement and to develop policy co-design capability. In essence, the aim is to involve users and the community in designing improved service delivery through building a co-design capability. This is part the everyday work that is done in the portfolio and of a broader service delivery reform program. It is also part of another major initiative in the portfolio about participation measures that was announced in May 2011. 
The first challenge has been to define what we mean by 'co-design'. As a current buzzword, people use it liberally and to describe a whole range of things. Consequently, it risks being falsely interchanged with other terms concerning community engagement, and concerning how we work with community.

At Medicare, however, our understanding of co-design is that it matches collaborative participation and design thinking with users, customers and stakeholder staff. By design thinking, I refer to those specific concepts and approaches that Christian Bason broaches in Chapter 5.

According to this thinking, collaborative participation involves challenging ourselves to work with customers and the community; it involves challenging ourselves to ask individuals about their own circumstances and human experiences. And, we think that engagement and participation should start as early as possible in the relationship.

While it may be easy to consult the public when general directions have been set, what is not easy is undertaking the observation work that Bason discussed, and using that to inform new strategic directions. As Lynelle Briggs points out (Chapter 7), this process also has the potential to inform policy thinking about broader agendas.

These are the issues with which DHS has been grappling. For DHS, co-design will be about blending design thinking with participation, with the expectation of improving customer experience.

As a portfolio, DHS wants to get feedback about what does and does not work on the ground, and to use that to shape our approach to design new services and work with the community.

DHS has a vision about what might be the best model for the portfolio. The techniques and tools that we currently use to engage with our customers include the 29 community forums that we have so far conducted. These were traditional community forums where we gathered groups together to have conversations about their views on service delivery. Their accounts of their customer service experience with DHS and their suggestions for improvements were the starting points for developing our co-design capability.

Our future goal is to build co-design capability to include customers, staff and stakeholders, potentially in the exploration phase (focusing on the issues we are facing in the portfolio) and then in the innovation phase (focusing on how we would prototype new co-design models and make them available for testing so as to evaluate their readiness for use in the creation of new services and programs). 
The past year has been spent in determining the model and methodology that we might need. We have also been looking at ways of harnessing customer insight. A live action project has started in Victoria, which involves conducting community engagement through our customer service officers and the relevant local municipal association in order consult with particular communities about issues that they face.

We have developed some guiding principles on the governance of our organisation with which staff will become familiar. In an organisation of over 40,000 people, it is fundamental to have a clear set of guiding principles so that our staff can be confident of the reform they are enacting in developing this new co-design model.

For the model itself, co-design will be applied both at the strategic part of the journey (thinking about what new ideas and strategic directions we are pursuing) and at the service design part of the process (harnessing some of the design techniques and practices discussed by Bason to refine particular projects or programs).

For us, co-design is the engine prototyping the application of design techniques; co-design allows rapid development, testing and evaluation that can be used to inform new projects and programs.

The idea is that co-design work - in which DHS works directly with its customers - is undertaken within a framework that makes the possible and viable clear. Customers have valuable expertise to offer to us about how new services and programs will impact on them, and they are well-placed to appraise performance once those services and programs are rolled out.

In addition to the broad community research conducted in 2010, Medicare has worked to improve service delivery by mapping a series of customer journeys to further expand the portfolio's understanding about particular customer groups, and also to obtain a picture of how our services are interacting with other events in peoples' lives. We have collaborated with external providers in conducting the research that has been the basis for the development of five detailed customer journeys. And these journeys are being rolled out across the portfolio.

One of the key insights that we have gained is that customers' journeys start long before we encounter them. In fact, customers are often not an individual; rather, they are part of a collective, a family. Additionally, they are relying on third parties, other organisations, to find out information, even before they come to us. Often when they come into our organisations, because of the way we currently organise and deliver our services, they are shoehorned into a 
particular program which might not necessarily meet all of their needs. This last finding is consistent with other research about customers wanting programs to be personal to them.

Another finding is that citizens, depending on what is happening in their lives and on how a service may or may not be delivered to them at a particular point, can fall into a particular life pattern. If DHS is able to recognise some of the trigger points or turning points in a life pattern, we may be able to achieve better outcomes for individuals by proactively reaching out to them.

The insights provided by the customer journeys have been enhanced in Victoria by information derived from 'community conversations'. The value of these conversastions lies in the opportunity to gather a community together to focus on DHS initiatives and how stakeholders can take responsibility for improving service delivery in their community.

We have also thought about the challenges in implementing our vision of codesign. Principally, they are about indentifying the opportunities for doing this detailed design work. Often in government, ideas arise quickly, sometimes influenced by the 24-hour media cycle. But, we must have the vision to look beyond this to determine how we can best pursue the notion of co-design to shape new initiatives, programs and policies for the future.

Jo Sammut: My contribution to this volume concerns a case study of a social program called Building Stronger Communities that was delivered in the Sydney suburb of Macquarie Fields, largely by Housing New South Wales. Accordingly, my contribution concerns not the design of a policy, but the implementation of it in the community.

Macquarie Fields, for most Australians, is known primarily as the site of a riot between residents and police in 2005. It is essentially an estate situated within a suburb, located 13 kilometres outside Campbelltown. It is a mixed, multicultural community, and many of its residents associate more with the Liverpool Local Government Association (LGA) than the Campbelltown LGA because Liverpool is closer.

The public housing sector, which is the principal demographic of Macquarie Fields, is characterised by socio-economic disadvantage. Prior to 2010, when Building Stronger Communities was implemented in Macquarie Fields, the school retention rate was low and the crime rate was high. Since 2010, improvements in both areas have been attributed to the success of Building Stronger Communities. 
Instituting this change was not an easy task. Critical to the success of the project was having a small team of three visionaries who were able to lead and implement it. We were not alone, but we had to see past what everybody else was thinking — and saying — to remain objective.

The Building Stronger Communities strategy resulted in practical changes, not only to our citizen engagement processes but also to the entire system of work performed by Housing New South Wales. The six sites that the project encompassed across New South Wales are currently being evaluated and, hopefully, some of the findings that are obtained through this process will benefit future strategy planning, public consultation and engagement for Housing New South Wales estates.

It has been written elsewhere in this volume that we must tailor engagement processes to sectors of the community - one model does not fit all - and that is what we managed to do with this particular strategy.

So what is Building Stronger Communities? In 2007 the then NSW premier, Morris Iemma, announced the strategy, to be led by Housing New South Wales, which was selected to lead the strategy because the common client group - or the common community - lived in social housing. The strategy was an investment of \$66 million - not just in Macquarie Fields, but across the state. The aim was to reduce the gap between disadvantaged public housing neighbourhoods and the surrounding neighbourhoods by getting the NGO sector, government, and business to work with the community.

That sounds fantastic, doesn't it? And could you imagine trying to do that in four years? We not only had to imagine it — we had to deliver it. The challenge was that Macquarie Fields at this time was a disengaged community that had had a government intervention following the social disturbance there in 2005. The community and the local NGOs were disillusioned with government local, state, or federal. And the interventions were not only coming from the state government, but also from the federal government (the National Action Plan, a federal government initiative, was a response to social disturbances in Cronulla, Lakemba and Macquarie Fields).

Hence, a community that felt vulnerable — but which was resilient — suddenly found itself flooded with various government interventions. If this were not challenging enough, our mandate in instituting the strategy involved engaging the community, the NGO sector, other government departments at local and state level, and our own Department of Housing. To us this was like having a polar attraction. The Department of Housing functions predominately as a manager; they are landlords, they manage tenants, and the agency's frontline staff generally had to deal with things like rental arrears, vacancies, noise, 
nuisance and annoyance, and a variety of personal issues they term as the 'fluffy' ones. For such an agency to deliver such a different sort of program was inevitably going to be a challenge.

There were often tensions between what we were trying to deliver - which was a government initiative - and the day-to-day work of the Department of Housing. This tension was exacerbated because the area had a high incidence of rental arrears. We had to do substantial marketing and communication to convince our colleagues and our clients to partcipate in the program.

Because of these challenges, we were forced to think innovatively in order to successfully implement the strategy. But, while we did this, we were hampered by political constraints. We had to deliver the program within four years and develop a Regeneration Partnership Plan that would be implemented by our partner government agencies, the NGOs, and the community.

For these reasons we often termed it 'the four year "speed dating" process' (although we did receive a six-month extension), and looked longingly to Victoria and Queensland, which both had eight years to do this sort of work.

And yet, we wanted to make sure this was a sustainable process. To build sustainability, one of our key focuses over the four years was to get citizens to recognise the short period of time available in which to make a change and that it would be necessary for them to carry on the mandate after our program had concluded. We wanted them to refashion and update the program because the priorities for the residents of Macquarie Fields are constantly changing.

We tried to build this desire for sustainability into the core business plan of the department and into its day-to-day responsibilities. But tensions remained because, even though some of the Department's policy supported our aims, the agency had another mandate, concerning their role as landlords and delivering associated services.

We made the Department responsible for particular areas of the strategy in Macquarie Fields, usually involving the physical infrastructure, such as the service specifications, building capacities, and funding arrangements. This meant that other services that were important for the regeneration plan would be delivered through other means and networks.

One of the first things we did was to get involved with other programs in the community, so as to establish a presence. We knew that we would face much cynicism, such was the fly-in, fly-out nature of previous efforts of these kinds.

We were honest from the outset, however, and said: 'We're only here for four years; this is what we have to work with; this is the timeframe; we want you to 
come along, we need you to come along, it's your community. At the end of the day we go home, you stay'. We took the same honest approach with the other agencies with which we worked.

Our next step was to form a Regeneration Planning Working Group, which was made up of representatives from government, NGOs, businesses and the community. The key focus of this group was the community engagement strategy.

Let me now outline the community visioning process that we underwent. Our planning process was six weeks. We then had eight weeks to collect community data. We were apprehensive about this, because we were convinced not only that the people of Macquarie Fields were sick of being consulted with, but also that there is enough data out there.

But, what we wanted was to hear people's responses. We wanted to get a feel for the area. We had enough Australian Bureau of Statistics, census and government data; what we needed instead was to consult with preschool and primary school students, churchgoers and teenagers. This, we felt, would give us a clearer picture of the demographics and particular needs in the area. To give you an idea of just how thorough we were in this endeavour, we even conducted surveys at the local pub.

Through the planning group, several working groups were formed, one of which was tailored for the strong and vibrant Indigenous community of Macquarie Fields. By doing this we wanted to make sure that the way the consultation would happen with each group would meet that group's needs.

We had a children's working party which explored the issue of how to engage with children, and we used paintings and drawings to do this (questions were created for kids so that they could answer them in these two mediums). With local primary school students, we also developed a poster outlining what they liked in Macquarie Fields, and what else they would like. When I look at that poster today, I see all the elements that we delivered in the regeneration plan. That in itself speaks volumes; it could very well be the poster for the regeneration partnership.

The poster had two sides: one depicting good elements about the community bike parks, skate parks and equipment; and the other showing the bad aspects rubbish, bullies, broken glass and needles. The children of one kindergarten class in the community made a DVD in which they portrayed what they liked about their community.

We also used the creative responses of the children to improve our engagement with the rest of the community. We collected the children's artwork and turned it into a calendar and art books, and included comments from the children. For 
example, one child said, 'If we get it done now it will be a better place'. The preschool kids developed the Christmas cards that became the official Christmas cards for the south-west region of the Department of Housing.

Our engagement processes targeted the broad community, community leaders, the NGOs, and the other government agencies. Each of these groups responded to surveys, findings and focus groups. From the findings of those engagement processes, we developed popular fact sheets, which included material designed by local children.

Additionally, around 1000 children's art books were produced. With the help of the private sector, we distributed these books to three local schools, and they were used as part of the schools' art classes.

From all the consultation that we undertook, we then formed what we called the implementation group to put in place key early intervention and prevention strategies. These included a focus on youth, as this demographic had been particularly neglected in Macquarie Fields in terms of the coordination between services. Young people told us that they wanted better service coordination. We managed to achieve this by ensuring that we had input into the specifications of services that were funded through the Department of Community Services.

Another important aspect of the regeneration partnership was its reporting mechanism. This was done quarterly as part of our four-year evaluation strategy, with reporting mandatory for each of the leading workgroups, the other government agencies and NGOs. In this way they were accountable to the Regeneration Partnership Plan, and they had to report against a template. The reason we did that was to make clear that this was not a Housing New South Wales Partnership Plan; it was a Regeneration Partnership Plan of all the agencies, the community, and the other service providers in the area.

Our goal of shifting peoples' assumption that this was a Housing New South Wales initiative required continuous community consultation as well as changes to our internal structures. We were fortunate that the team leader of the local office was engaged in community development, and was people-focused, rather than arrears-focused. The team leader was also respected by the community in Macquarie Fields - something that is novel in a housing estate. He was able to transfer some of this community respect to his team, to the benefit of the entire project.

Our community consultation succeeded because of our flexibility: we did it anytime and anywhere. And, if a particular approach didn't work, we tried something different. When one street, for example, was letterbox-dropped a few days before a meeting about upgrading a nearby park, we noticed no one was collecting the letter. So instead we raised awareness of the project by 
doorknocking on a Saturday morning; we succeeded in having people consult with us in their pyjamas, over the bonnets of their cars, at 9 am. We were able to listen to peoples' ideas about their area. Ultimately, these consultations on the upgrade to the park led to the once rubbish-strewn landscape of that area now being regenerated with rockery and trees.

In all the strategies we undertook we had a 'give back' policy: if we were serious about changing the public space, we had to incorporate all members of the community. For example we invited some former graffiti taggers in the area to be involved in murals we called 'community arts' (the local council would not allow us to call it 'graffiti art'). We were able to get them on board through consultation strategies encompassing community leaders, local teams, youth services and other government level agencies.

But this whole project was no smooth road; in nearly everything we did, we encountered resistance. But we also had resilient staff who were intent on including those around them in this endeavour.

An example of community resistance was seen in a particular park in Macquarie Fields that had previously only been used once or twice a year. We wanted to upgrade it to make it a hub for the community. But, when we went out to talk to people about this park, though they had some great ideas, they wanted to see a six foot fence surrounding the whole area and somebody holding the key. The perception was that if anything was done in Macquarie Fields it would just be destroyed within a couple of days.

And it was our team that was saying, 'No, no, no, we'll put all these things in place with the community, and you will be part of the process.' And it was. The community led this process, and eventually sent leaders of the Indigenous community of Macquarie Fields to inspect different community parks across Sydney; after this, they drew basic designs for their ideal park.

That initial design stayed largely intact - there were only a few minor changes from the landscape architects. The community stayed involved by painting the 'snake trail', which became a bike trail and an exercise station circuit. It also made an appearance on the SBS gardening and lifestyle programme Costa's Garden, such was the success of the community engagement - and ownership - that led to the creation of this park.

These projects also served to bridge a gap within the community. Pupils from both local schools grew gardens together and helped to plant trees in the park's eucalyptus reserve. Previously, even though they were located less than 400-metres apart, the two schools had had little collaboration with one another and had only communicated when they had to transfer students from one school to the other. 
All of this was achieved because of the community engagement and capacity building processes that we had developed. We may have been the ones driving the project, but there were many others who came on board and helped achieve its end.

Having succeeded in the community engagement and capacity building goals of the Regeneration Plan, we moved to the transition phase, in which we handed over responsibility to the community for the ongoing project tasks. These tasks included graffiti eradication, rubbish removal, and redevelopment of public spaces. As the first part of our exit strategy, we conducted in September 2010 one final consultation with the community, this time using a new online survey system called Survey Monkey. As part of that process, we developed a transition plan and made other parts of other government agencies, NGOs, and the community responsible for delivering parts of it. We also utilised the internet to ask the community what changes they had seen since we began working with them. This was an extension of a community visioning exercise that we had undertaken five years beforehand, in which we asked people what they wanted Macquarie Fields to resemble in five years.

I predict that some of the project will drop off because the community in particular cannot be held accountable like we can; however, for now at least, much of the project is being followed through. The challenge will be whether the governance structures remain in place, because it is the governance structures that manage that whole implementation of the transition plan. 